\title{
The Verification and Validation of the Ray-tracing of Bag of Triangles (BoTs)
}

\author{
by Charith Ranawake
}




\section{NOTICES}

\section{Disclaimers}

The findings in this report are not to be construed as an official Department of the Army position unless so designated by other authorized documents.

Citation of manufacturer's or trade names does not constitute an official endorsement or approval of the use thereof.

Destroy this report when it is no longer needed. Do not return it to the originator. 


\title{
Army Research Laboratory
}

Aberdeen Proving Ground, MD 22105

\section{The Verification and Validation of the Ray-tracing of Bag of Triangles (BoTs)}

\author{
Charith Ranawake \\ Survivability/Lethality Analysis Directorate, ARL
}

Under contract

W911NF-10-2-0076 


\section{REPORT DOCUMENTATION PAGE}

Public reporting burden for this collection of information is estimated to average 1 hour per response, including the time for reviewing instructions, searching existing data sources, gathering and maintaining the data needed, and completing and reviewing the collection information. Send comments regarding this burden estimate or any other aspect of this collection of information, including suggestions for reducing the burden, to Department of Defense, Washington Headquarters Services, Directorate for Information Operations and Reports (0704-0188), 1215 Jefferson Davis Highway, Suite 1204, Arlington, VA 22202-4302. Respondents should be aware that notwithstanding any other provision of law, no person shall be subject to any penalty for failing to comply with a collection of information if it does not display a currently valid OMB control number.

PLEASE DO NOT RETURN YOUR FORM TO THE ABOVE ADDRESS.

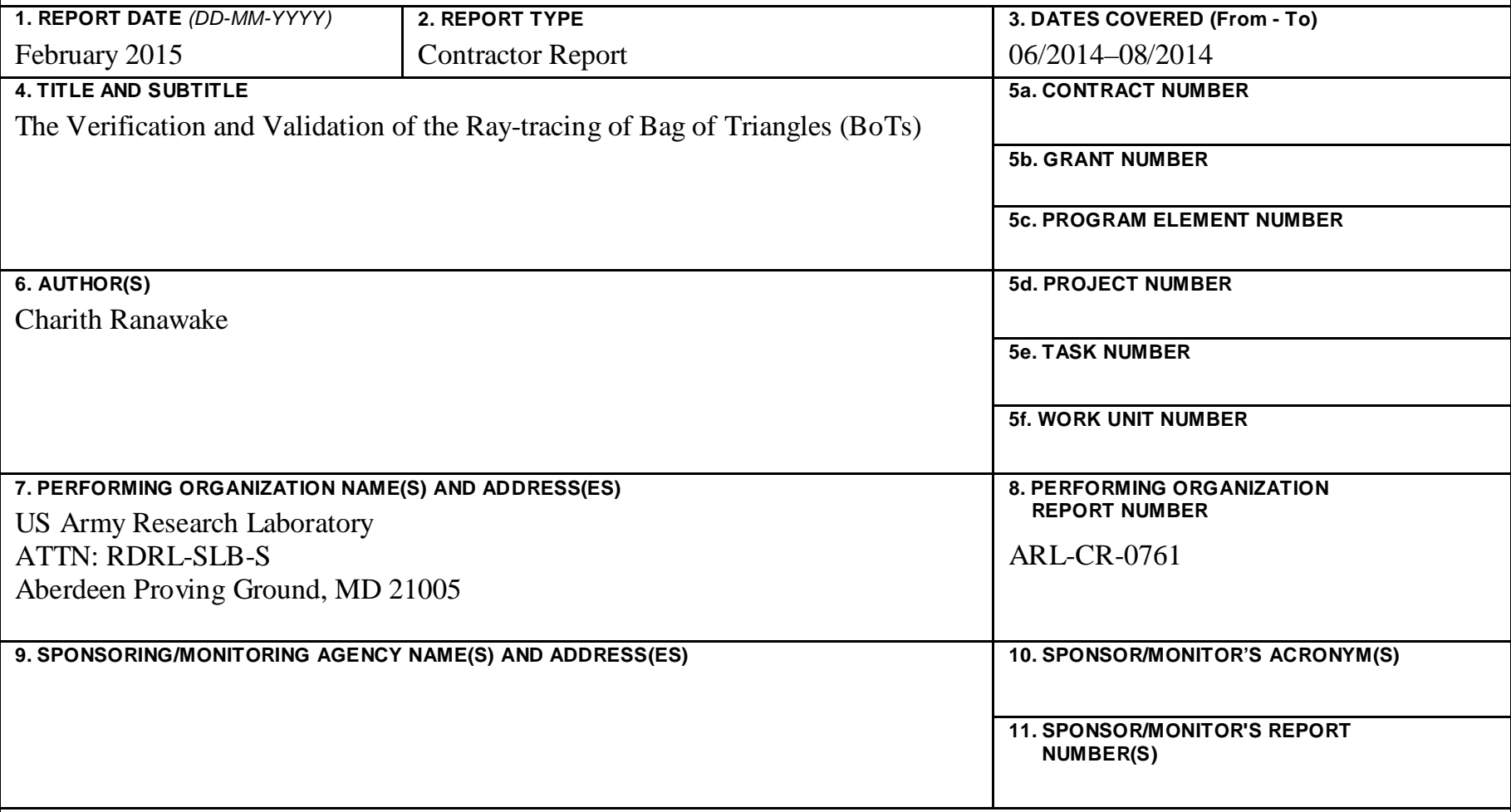

\section{DISTRIBUTION/AVAILABILITY STATEMENT}

Approved for public release; distribution unlimited.

\section{SUPPLEMENTARY NOTES}

POC: Geoffrey Sauerborn

\section{ABSTRACT}

This report will cover the testing of the Ballistic Research Laboratory-Computer-Aided Design's (BRL-CAD's) ray-tracer on the primitive Bag of Triangles (BoTs). Two programs were created to accommodate each component of this project. The first program created all possible triangles (BoTs) given a bounding box and step size that is specified by the user. The second program fired multiple rays toward various locations on each triangle in the database. The results of these tests were classified as a success or failure; the percentages of success were graphed against the different tolerance levels to determine the accuracy of the ray-tracer on BoTs. These data could be useful in understanding how BRL-CAD's ray-tracer performs in comparison to the Air Force's ray-tracer, FASTGEN, on BoTs.

\section{SUBJECT TERMS}

BRL-CAD, Ray-trace, BoTs

\section{SECURITY CLASSIFICATION OF:}

Unclassified

b. ABSTRACT

Unclassified

\section{c. THIS PAGE}

Unclassified

\begin{tabular}{|c|c|}
$\begin{array}{c}\text { 17. LIMITATION } \\
\text { OF } \\
\text { ABSTRACT } \\
\text { UU }\end{array}$ & $\begin{array}{c}\text { 18. NUMBER } \\
\text { OF } \\
\text { PAGES }\end{array}$ \\
& 18
\end{tabular}

19a. NAME OF RESPONSIBLE PERSON Geoffrey Sauerborn 19b. TELEPHONE NUMBER (Include area code) 410-278-6178 


\section{Contents}

List of Figures $\quad$ iv

List of Tables $\quad$ iv

$\begin{array}{ll}\text { Acknowledgments } & \text { v }\end{array}$

Student Bio

1. Introduction/Background $\quad 1$

2. Experiment/Calculations $\quad 1$

$\begin{array}{lrr}\text { 3. } & \text { Results and Discussion } & 6\end{array}$

$\begin{array}{lr}\text { 4. Summary } & 8\end{array}$

5. References and Notes $\quad 9$

$\begin{array}{lr}\text { Distribution List } & 10\end{array}$ 


\section{List of Figures}

Fig. 1 All possible triangles within bounding box $(1,1,1)$ with step size of $0.5 \ldots \ldots \ldots \ldots \ldots \ldots \ldots . . . . . .2$

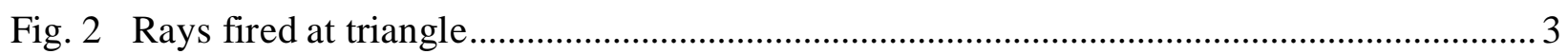

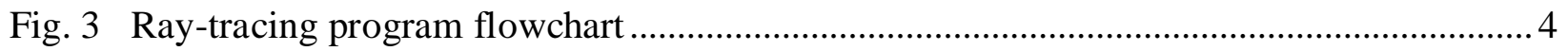

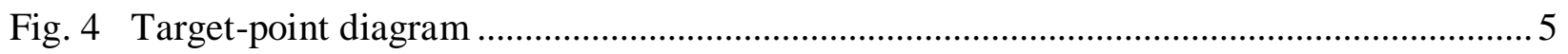

Fig. 5 Coordinates of a point dividing a line segment.............................................................. 5

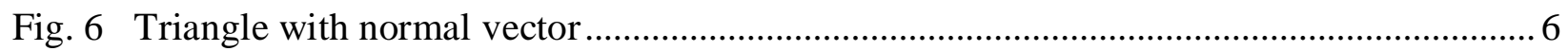

Fig. 7 Data for the percentage of successes for the bounding box $(2,2,2)$ with step size $1.5 \ldots . .7$

\section{List of Tables}

Table Data for the ray-trace of BoTs for the bounding box $(2,2,2)$ with step size 1.5 .............. 7 


\section{Acknowledgments}

The author wishes to acknowledge the mentorship of Mr Sean Morrison and Mr Geoffrey Sauerborn. 


\section{Student Bio}

Charith Ranawake is attending the University of Maryland College Park as a freshman in Computer Science. Before working on Ballistic Research Laboratory-Computer-Aided Design (BRL-CAD) this summer, he worked as a volunteer programmer with a professor at George Mason University where he helped develop a computer-security software package. Charith is a graduate of Marriotts Ridge High School in Ellicott City, Maryland. 


\section{Introduction/Background}

The Ballistic Research Laboratory-Computer-Aided Design (BRL-CAD) is a solid geometry modeling CAD system that assists the users in constructing and analyzing complex structures that would otherwise require advanced computations. ${ }^{1,2}$ BRL-CAD uses a tool called the raytracer $^{3}$ to help analyze solid objects. ${ }^{4,5}$ This tool has the ability to quickly render graphics and perform various operations pertinent when analyzing such geometries as BoTs (Bag of Triangles). ${ }^{6}$ A BoT is generally used to represent triangle mesh objects in BRL-CAD. BoT objects have several modes, such as surface mode, volume mode, and plate mode. The mode that was primarily used throughout this project is the plate mode, which is used to represent a solid object in the form of a sheet with a small uniform thickness.

The goal of this project was to create all possible triangles of variegated designs, lengths, and angles within a specified finite range and then to perform tests to assess the functionality of the ray-tracer on these objects. These tests were used to gather information on whether the ray-tracer can hit points at various locations relative to each triangle, such as hitting directly on the triangle or just slightly exterior to the triangle. The ability to extensively test the BRL-CAD's ray-tracer on BoTs will be useful in identifying the baseline accuracy of the ray-tracer and then in identifying ways to improve its accuracy. Having a baseline test will eventually allow the BRLCAD ray-tracer to yield comparative results that could be assessed relative to itself or to other ray-tracers (such as FASTGEN, a ray-tracer popular in many US Air Force applications).

\section{Experiment/Calculations}

This project was approached by modifying 2 example programs in the BRL-CAD source code. The first program, wdb_example.c, creates a database of BoTs by reading information about the triangles from a file. wdb_example.c was modified to create the database of BoTs for this project. The second program, rtexample.c, implements a sample ray-tracer by loading a triangle from a database and firing a single ray toward a point relative to the triangle and in a direction normal to the triangle. The rtexample.c was modified to fire rays at a multitude of points relative to each triangle in the database and at various tolerance levels.

The wdb_example.c was used as a starting point and modified to create a new program, (wdb_triangle.c) that would generate all possible BoTs. This process required several steps. Initially, wdb_triangle.c was modified to create a database of a single triangle using user specified coordinates of the 3 vertices input from the command line. This program was then expanded to create all possible triangles for a bounding box and a step size in the $\mathrm{x}, \mathrm{y}$, and $\mathrm{z}$ directions specified by the user. The BRL-CAD library function for creating BoTs, mk_bot, was 
continually called during each iteration of the 9 nested for-loops in the main function to create a triangular object in the database for each possible combination of vertices. This resulted in multiple objects in the database that had the appearance shown in Fig. 1 when opened using the graphics interface application, MGED.

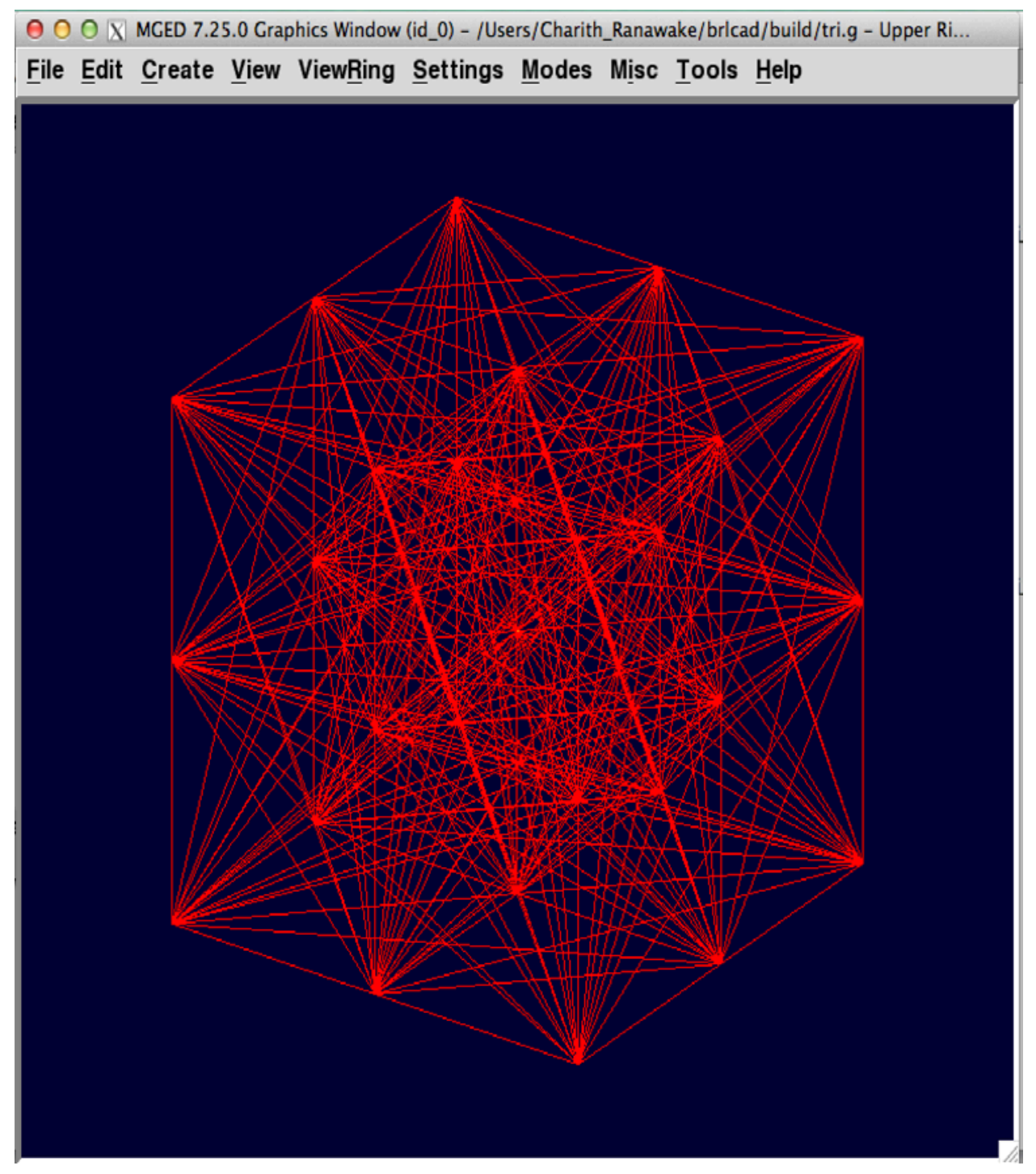

Fig. 1 All possible triangles within bounding box $(1,1,1)$ with step size of 0.5

A ray-tracing program, rt_bot.c, was then implemented to fire rays at several locations, both on and off the triangle, for every triangular object in the database that was created by wdb_triangle.c. These locations are shown in Fig. 2. 


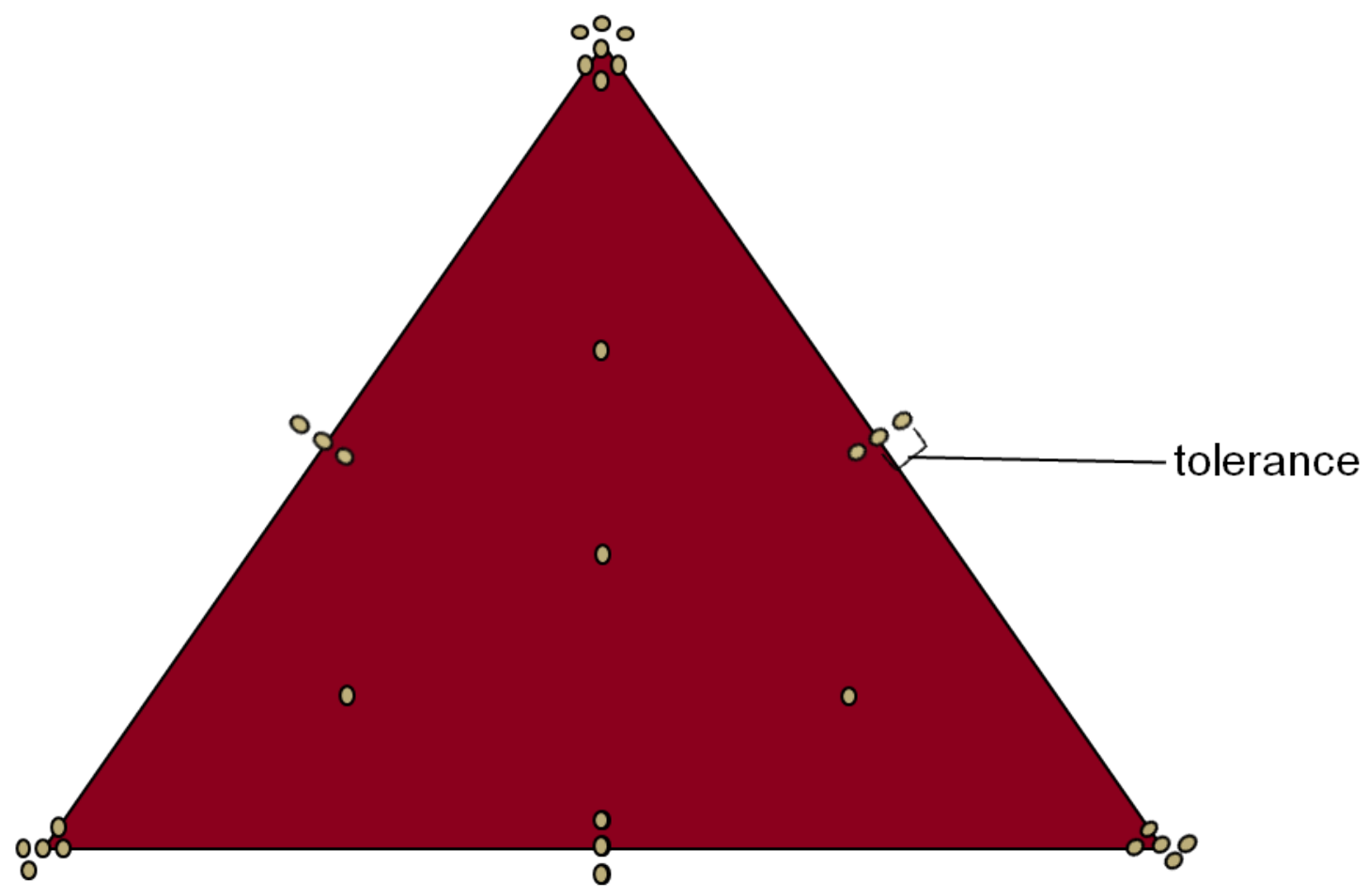

Fig. 2 Rays fired at triangle

Figure 3 shows the basic outline of the ray-tracing program, rt_bot.c. The main program has the same basic structure as the corresponding wdb_triangle.c program that created the BoTs. The user inputs the bounding box and the step size of the program as runtime arguments. The program uses 9 nested for-loops for incrementing vertex coordinates. For each combination of vertices that forms a triangle, wdb_triangle.c loads the corresponding object from the BoT database and calls a function for performing the ray-tracing on the triangle. As mentioned before, ray-tracing involves calculating the coordinates of the target point, the unit normal to the triangle, and the coordinates of the firing point. The ray-tracing function also maintains counters to hold such information as the number of rays fired and the number of successes (hits or misses). For interior target points, vertices, and edges, a success occurs when the ray-tracer records a hit. For an exterior point, a success occurs when the ray-tracer records a miss. 


\section{Start}

Initialize variables for ray-tracer

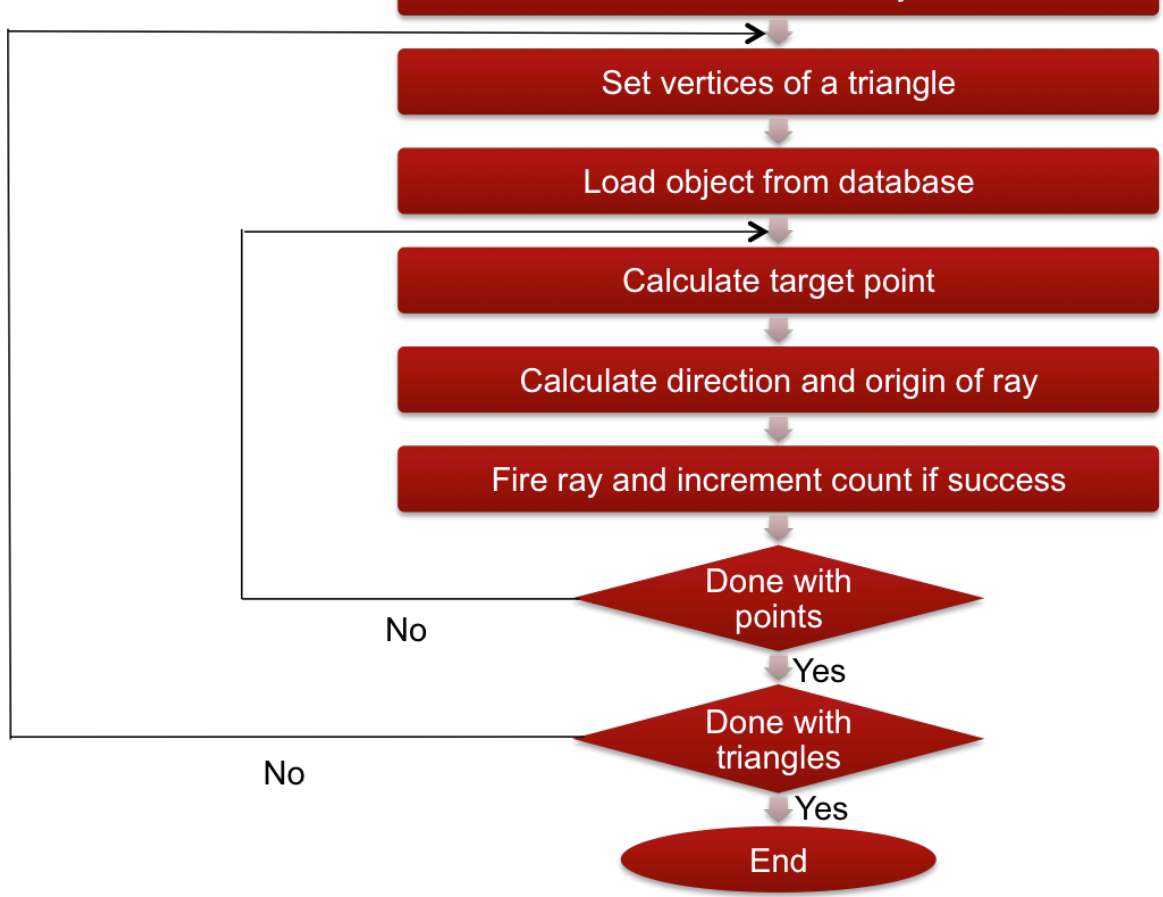

Fig. 3 Ray-tracing program flowchart

Several steps are involved when determining the $\mathrm{x}, \mathrm{y}$, and $\mathrm{z}$ coordinates for a target point. Figure 4 shows an example in which the target point is interior to the triangle and on the median joining vertex B to mid-point of line AC. The first step is to calculate the midpoint, D of line BC, as the target-point coordinates:

$$
x_{4}=\frac{\left(x_{1}+x_{3}\right)}{2}, y_{4}=\frac{\left(y_{1}+y_{3}\right)}{2}, z_{4}=\frac{\left(z_{1}+z_{3}\right)}{2} .
$$

Then the distance BD, which we will call " $\mathrm{L}$ " the distance to the target point, is calculated from using the formula below:

$$
L=\sqrt{\left(x_{2}-x_{4}\right)^{2}+\left(y_{2}-y_{4}\right)^{2}+\left(z_{2}-z_{4}\right)^{2}} .
$$




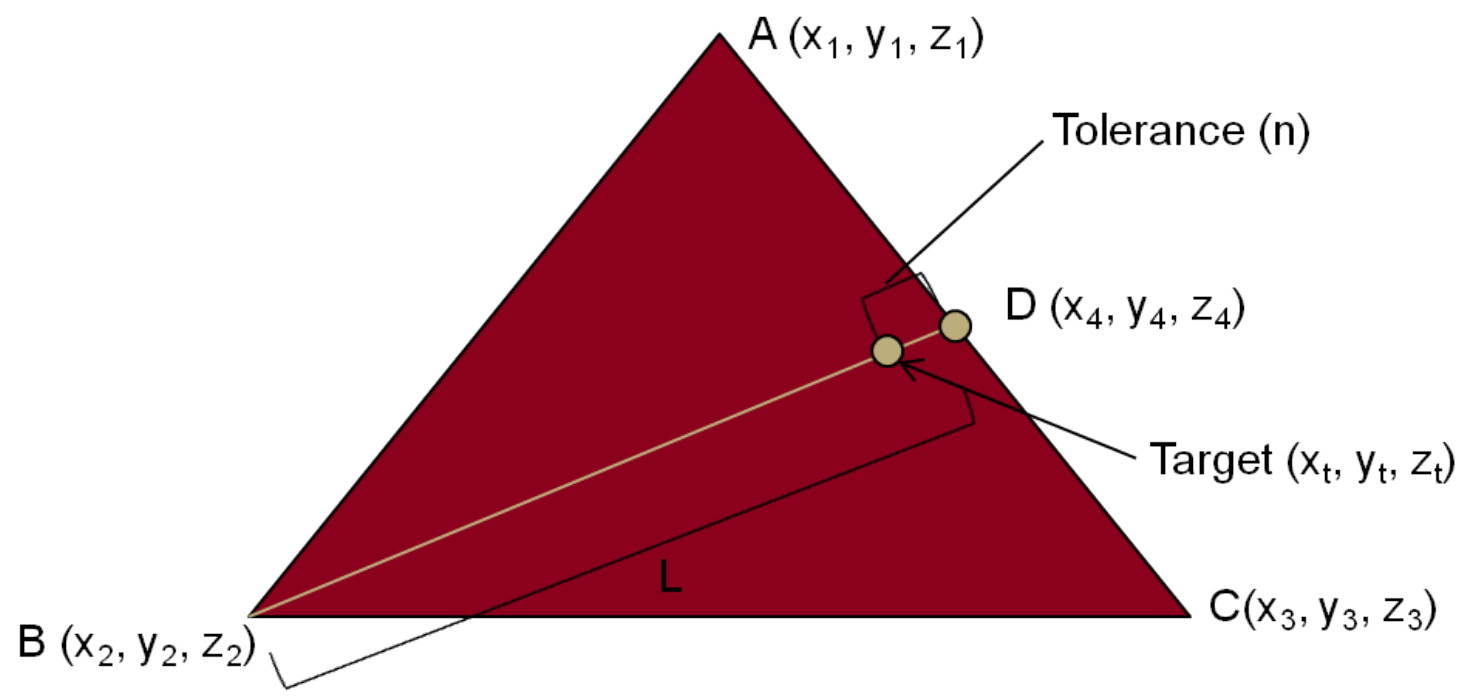

Fig. 4 Target-point diagram

The target point is calculated using Fig. 5 by applying the following proportion formula:

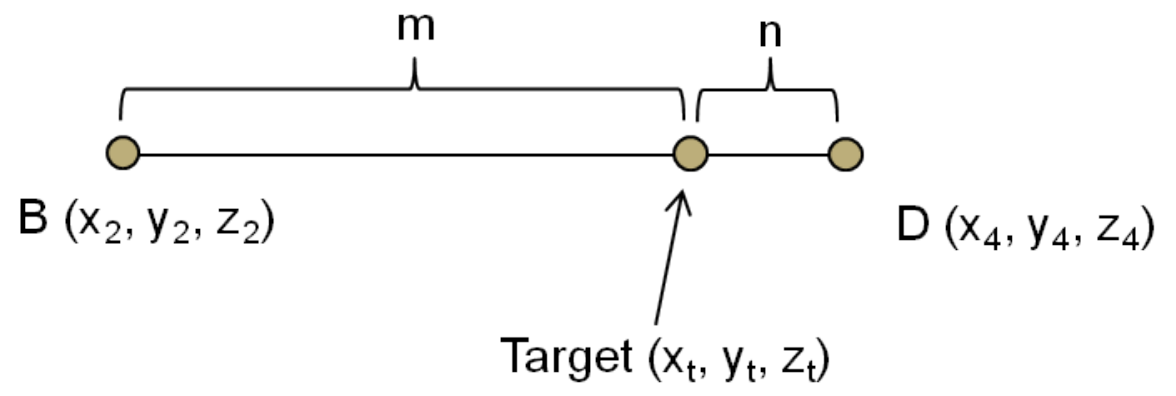

Fig. 5 Coordinates of a point dividing a line segment

Where the target-point coordinates $\left(\mathrm{x}_{\mathrm{t}}, \mathrm{y}_{\mathrm{t}}, \mathrm{z}_{\mathrm{t}}\right)$ are calculated by Eq. 3 using the proportional distances $m$ and $n$ relative to $L$, where $m=L-n$, and $n=$ tolerance

$$
\begin{aligned}
& x_{t}=\frac{m x_{4}+n x_{2}}{m+n} \\
& y_{t}=\frac{m y_{4}+n y_{2}}{m+n} \\
& z_{t}=\frac{m z_{4}+n z_{2}}{m+n}
\end{aligned} .
$$

These calculations are specifically for points that are interior to the triangle. The exterior points can be calculated in a similar manner using a slightly different formula. 
In addition to the target point, the firing direction and the firing point were calculated. Figure 6 shows the case where a ray is fired from the firing point $\left(x_{f}, y_{f}, z_{f}\right)$ in a direction normal to the triangle.

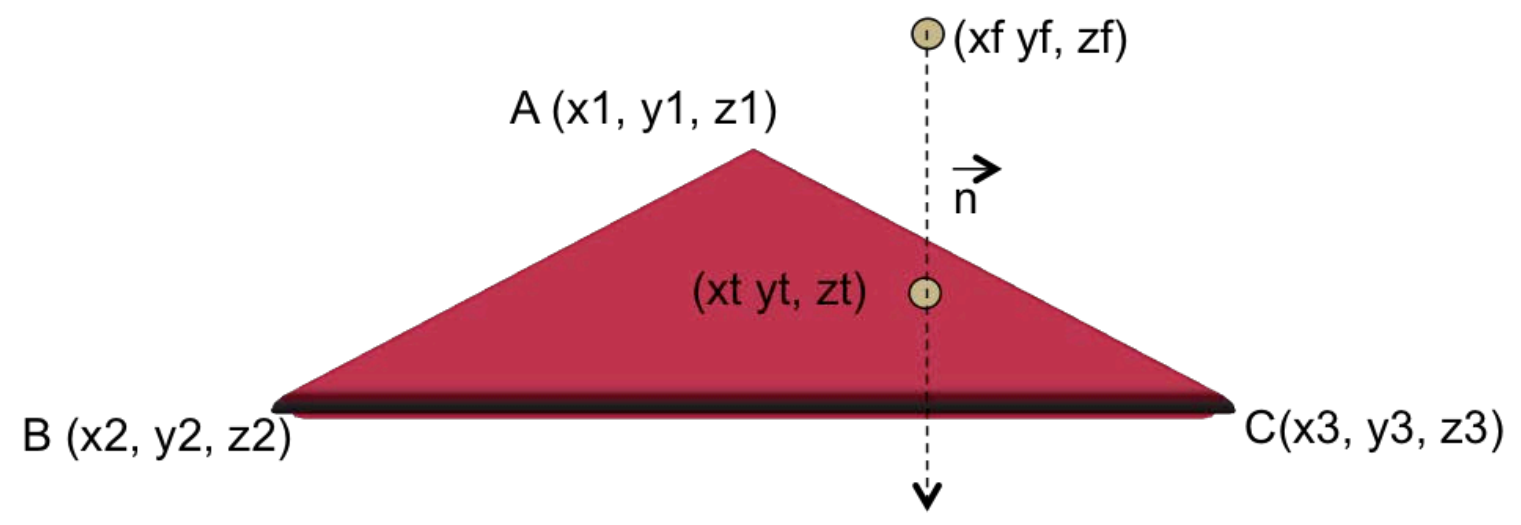

Fig. 6 Triangle with normal vector

Using the coordinates of the target point, the firing point and the direction of the ray were calculated as follows:

- Step 1: Calculate normal to $\triangle \mathrm{ABC}$ using the cross product of 2 vectors (Ex: $\mathrm{AB} \times \mathrm{AC})$.

- Step 2: Calculate the unit vector $n=<n_{x}, n_{\boldsymbol{y}}, n_{z}>$ of the cross product.

- Step 3: Determine the coordinates of the firing point $\left(x_{f}, y_{f}, z_{f}\right)$ as the following:

$$
\begin{aligned}
& x_{f}=x_{t}-h n_{x} \\
& y_{f}=y_{t}-h n_{y} \\
& z_{f}=z_{t}-h n_{z} .
\end{aligned}
$$

\section{Results and Discussion}

To test the performance of the ray-tracer, a BoT was created for the bounding box $(2,2,2)$ with the step size of 1.5. This created a database of 336 triangles. Then the ray-tracer program was executed on the set of triangular objects; the number of successes and the number of attempts were recorded for each type of target point. The data are tabulated in Table 1. Figure 7 is a bar chart showing the variation of percentage of successes with the type of target point. The data show that the ray-tracer recorded $100 \%$ success for interior points as expected. Also, as the 
tolerance increased from 0.00001 to 0.1 , the percentage of successes increased from $91 \%$ to $95 \%$. The ray-tracer recorded the smallest percentage of successes when the target point was on a vertex or edge. From these results, it can be concluded that BRL-CAD's ray-tracer is fairly accurate for target points that are interior to the triangle as well as target points that are small tolerance levels away from the edges and vertices. However, the accuracy decreased as the rays were fired at a target point that was on a vertex or edge.

Table Data for the ray-trace of BoTs for the bounding box (2, 2, 2) with step size 1.5

\begin{tabular}{|l|l|l|l|}
\hline \multicolumn{4}{|c|}{ Database: Triangles (336) } \\
\hline \multicolumn{1}{|c|}{ Type } & Successes & Attempts & \multicolumn{1}{c|}{ Percentage (\%) } \\
\hline Interior & 1344 & 1344 & 100 \\
\hline Vertex/Edge & 1710 & 2016 & 84.82142857 \\
\hline Tolerance - 0.1 & 5802 & 6048 & 95.93253968 \\
\hline Tolerance - 0.001 & 5772 & 6048 & 95.43650794 \\
\hline Tolerance - 0.00001 & 5528 & 6048 & 91.4021164 \\
\hline
\end{tabular}

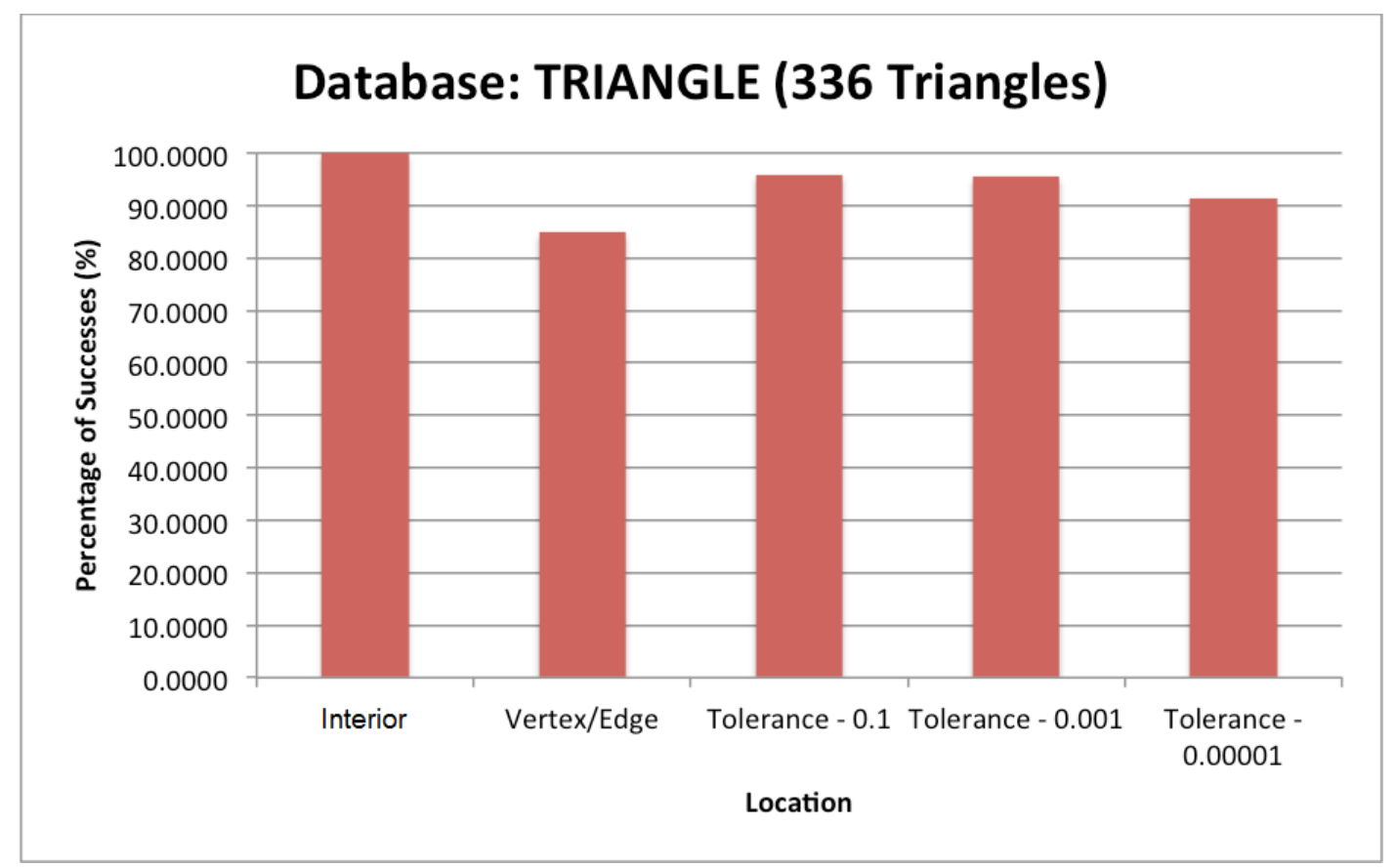

Fig. 7 Data for the percentage of successes for the bounding box $(2,2,2)$ with step size 1.5 


\section{Summary}

In this project, BRL-CAD's ray-tracer was tested on the primitive Bag of Triangles (BoTs). Two programs were created to accomplish these tests. The first program created numerous triangles or objects in the database, while the second program was used to fire rays at each object. Based on the results, the ray-tracer was very accurate on points on the interior of the triangles and small tolerances away from the vertices and edges. But the accuracy of the ray-tracer decreased significantly when tested on edge or vertex points. 


\section{References and Notes}

1. About BRL-CAD. BRL-CAD [accessed 2015 Jan 13]. http://brlcad.org/d/about.

2. Feature Overview. Contributors' Guide to BRL-CAD [accessed 2014 Aug 22]. http://en.flossmanuals.net/contributors-guide-to-brl-cad/feature-overview/.

3. There actually are several ray-tracing algorithms available to select within BRL-CAD. This report describes fitness testing that is applicable for any of these ray-tracer algorithms. Therefore, for purposes of this report they are singularly referred to as "the ray-tracer".

4. NMG raytracing performance improvement. BRL-CAD [accessed 2015 Jan 13]. http://brlcad.org/wiki/NMG_Raytracing_Performance_Improvement.

5. Ray tracing (graphics). Wikipedia, the free encyclopedia [accessed 2015 Jan 13]. http://en.wikipedia.org/wiki/Ray_tracing_(graphics).

6. BoT. BRL-CAD [accessed 2015 Jan 13]. http://brlcad.org/wiki/BoT. 


$\begin{array}{cl}1 & \text { DEFENSE TECHNICAL } \\ \text { (PDF) } & \text { INFORMATION CTR } \\ & \text { DTIC OCA } \\ 2 & \text { DIRECTOR } \\ (\mathrm{PDF}) & \text { US ARMY RESEARCH LAB } \\ & \text { RDRL CIO LL } \\ & \text { IMAL HRA MAIL \& RECORDS MGMT } \\ 1 & \text { GOVT PRINTG OFC } \\ (\mathrm{PDF}) & \text { A MALHOTRA } \\ 6 & \text { DIRECTOR } \\ \text { (PDF) } & \text { US ARMY RSRCH LAB } \\ & \text { RDRL SLB S } \\ & \text { M PERRY } \\ & \text { W BOWMAN } \\ & \text { S MORRISON } \\ & \text { N REED } \\ & \text { G SAUERBORN } \\ & \text { C YAPP }\end{array}$

